This item was submitted to Loughborough's Research Repository by the author.

Items in Figshare are protected by copyright, with all rights reserved, unless otherwise indicated.

\title{
The effect of uphill and downhill slopes on weight transfer, alignment and shot outcome in golf
}

\section{PLEASE CITE THE PUBLISHED VERSION}

https://doi.org/10.1123/jab.2017-0310

\section{PUBLISHER}

(c) Human Kinetics, Inc.

\section{VERSION}

AM (Accepted Manuscript)

\section{PUBLISHER STATEMENT}

This work is made available according to the conditions of the Creative Commons Attribution-NonCommercialNoDerivatives 4.0 International (CC BY-NC-ND 4.0) licence. Full details of this licence are available at: https://creativecommons.org/licenses/by-nc-nd/4.0/

\section{LICENCE}

CC BY-NC-ND 4.0

\section{REPOSITORY RECORD}

Blenkinsop, Glen, Ying Liang, Nicholas J. Gallimore, and Michael Hiley. 2019. "The Effect of Uphill and Downhill Slopes on Weight Transfer, Alignment and Shot Outcome in Golf". figshare. https://hdl.handle.net/2134/33675. 
Journal of Applied Biomechanics **, ******

\title{
The effect of uphill and downhill slopes on weight transfer, alignment and shot outcome in golf
}

\author{
Glen M. Blenkinsop ${ }^{1}$, Ying Liang², Nicholas J. Gallimore ${ }^{3}$, and Michael J. Hiley ${ }^{1}$ \\ ${ }^{1}$ School of Sport, Exercise \& Health Sciences, Loughborough University, Loughborough, UK \\ 2Department of Physical Education, Anhui Normal University, Beijing East Road, Wuhu, China \\ ${ }^{3}$ Vicon Motion Systems Ltd, Oxford, UK
}

\begin{abstract}
The aim of the study was to examine changes in weight transfer, alignment and shot outcome during golf shots from flat, uphill, and downhill slopes. Twelve elite male golfers hit 30 shots with a six-iron from a computer assisted rehabilitation environment (CAREN) used to create $5^{\circ}$ slopes while collecting $3 \mathrm{D}$ kinematics and kinetics of the swing. A launch monitor measured performance outcomes. A shift in the centre of pressure was found throughout the swing when performed on a slope, with the mean position moving approximately $9 \%$ closer to the lower foot. The golfers attempted to remain perpendicular to the slope, resulting in the weight transfer towards the lower foot. The golfers adopted a wider stance in the sloped conditions and moved the ball towards the higher foot at address. Ball speed was not significantly affected by the slope, but launch angle and ball spin were. As predicted by the coaching literature, golfers were more likely to hit shots to the left from an uphill slope and to the right for a downhill slope. No consistent compensatory adjustments in alignment at address or azimuth were found, with the change in final shot dispersion due to the lateral spin of the ball.
\end{abstract}

\section{INTRODUCTION}

Golf courses are designed to incorporate the natural features of the surrounding area, such as using slopes to make the course more challenging. Previous golf studies typically take place in controlled laboratories with shots taken into a net from a flat surface 1,2,3,4 whilst kinematic and kinetic data are collected. $4,5,6,7$ Such studies have provided useful insight into the mechanics and performance of the golf swing, and have shown that centre of pressure (COP) motion (weight transfer) during the golf swing has strong correlations with the production of club head velocity. ${ }^{8,9,10}$ However, golf courses are variable environments, where conditions can change from shot to shot. A game of golf is more than likely to include uneven ground, requiring shots to be played from an uphill or downhill slope. The inclination between the golfer's feet and the ball of 22 professional players over 16 different courses has been measured, and it was found that approximately $80 \%$ of shots were played from a slope of between $\pm 1^{\circ}$ and $10^{\circ}$, with an average inclination of $4.6^{\circ}(n=953) .{ }^{11}$

Golf coaching literature often stresses the importance of the correct weight transfer pattern throughout the golf swing. ${ }^{12,13}$ A typical weight transfer sequence will begin with an even distribution between the feet at address. ${ }^{12}$ The golfer's weight then moves towards the back foot during the back swing, before moving towards the front foot just before the start of the down swing. ${ }^{5}$ For the majority of golfers a rapid transfer of weight towards the front foot then occurs from the early stage of the downswing through to ball contact and follow-through (Figure 1, black line)..$^{5}$ It has been shown that for approximately a third of golfers the pattern deviates from the above with the weight moving towards the back foot (reverse group) at ball contact (Figure 1, grey line). ${ }^{5}$ Popular coaching literature for playing off uneven surfaces has been derived from playing and coaching experience. ${ }^{12,14}$ Advice suggests the golfer sets the body perpendicular to the slope and adopts a stance that is wider than normal to increase stability. ${ }^{12,14,15} \mathrm{~A}$ setup with the body perpendicular to the slope will result in more weight transferred to the lower foot, causing a general weight shift to the back foot on 
uphill slopes and to the front foot during downhill slopes. On the other hand, Leadbetter and Harmon advise the golfer to counter the natural urge to sway down the slope by moving weight to the back foot for downhill slopes and to the front foot for uphill slopes, i.e. lean into the hill slightly. ${ }^{12,15}$ Leadbetter also advises the golfer to move the ball nearer the front foot for uphill slopes and nearer the back foot for downhill slopes whilst putting more emphasis on swinging the arms and less on turning the body to assist in maintaining balance. ${ }^{12}$ A shift in the COP might be expected when playing on a slope, however, are the patterns of movement described in the literature maintained ${ }^{5}$

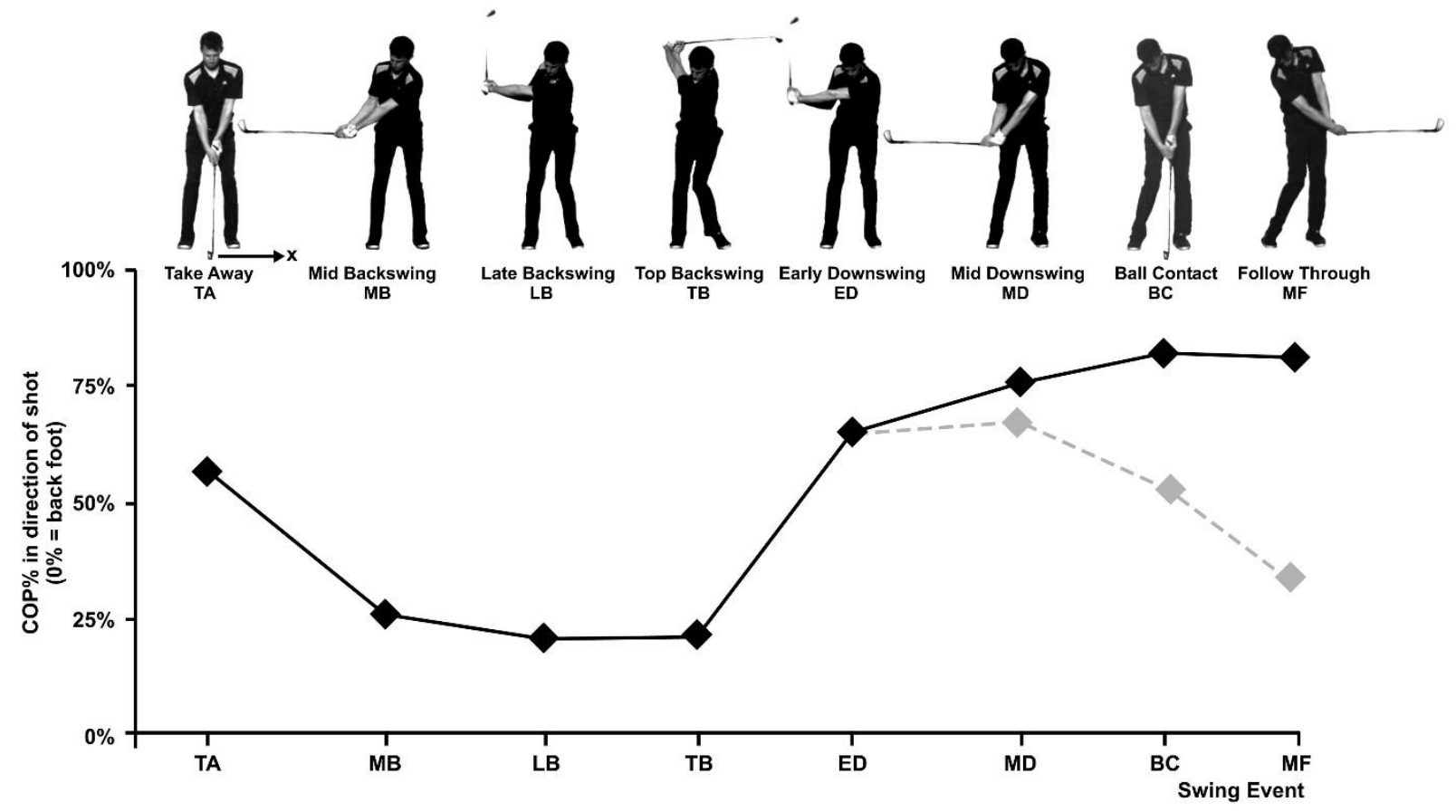

Figure 1. Swing events within the golf shot along with the weight transfer from back foot (furthest from target) to front foot (adapted from Ball and Best, 2007). Dashed grey line represents the "reverse" group identified by Ball and Best (2007).

In addition to adjusting weight distribution the golfer may also adjust how they address the ball in terms of the direction they intend to hit it. The coaching literature suggests that uphill shots will tend to land to the left of a centrally aligned target and downhill shots will tend to land to the right (for a right-handed player). It has been recommended that this can be compensated for by rotating the trunk to the right or left of the target at address, respectively. ${ }^{15}$ However, an experienced golfer may choose to "shape" the shot, with a "fade" or a "draw", rather than change the direction of aim. A "fade" will move the ball from left to right in the air countering the right to left tendency of an uphill slope. ${ }^{15,16}$ A typical setup for a fade is to "open the stance" with the feet and body pointing to the left of the target. ${ }^{12,17}$ Conversely, a setup with the feet and body pointing to the right of target (closed stance) can produce a "draw" where the ball moves from right to left in the air. It might be expected that skilled golfers would make an adjustment to counter the effects of a slope, but whether they adjust the aim or the shape of the shot is unknown.

The aim of the present study was to examine changes in weight transfer, direction of aim and performance outcomes (e.g. ball speed, launch angle and offline displacement) during golf shots from flat, uphill, and downhill slopes. It is hypothesised for uphill shots the golfers' COP will shift towards the back foot, the launch angle will increase with a ball spin to the left, the hips and shoulders will be aligned to the right at address 
(relative to the flat condition) and that golfers will place the ball closer to the front foot compared to the flat condition. For shots from a downhill slope the golfers' COP will shift towards the front foot, the launch angle will decrease with a ball spin to the right, the hips and shoulders will be rotated to the left and the ball will be placed closer to the back foot.

\section{METHODS}

Twelve male right handed amateur golfers, classed as expert, (age: $26 \pm 9$ [mean \pm standard deviation] years, mass: $82 \pm 7 \mathrm{~kg}$, height: $1.83 \pm 0.08 \mathrm{~m}$ ) with a mean handicap of $1.6 \pm 2.4$ (range: -3 to 5) participated in the study. All golfers, who were free from injury, gave written informed consent for participation in the study that was approved by the university ethical advisory committee.

\section{Data collection}

Following a self-selected warm-up, golfers hit 30 shots, with 10 shots from three different slope conditions (flat, uphill, and downhill), towards a point located in the middle of a net positioned three metres away (Figure 2). Golfers were asked to hit straight shots (i.e. so the ball landed as close to the centre line of the virtual driving range provided by the launch monitor) using their own six-iron club, and the Titleist golf balls provided (DT Solo, Titleist, Massachusetts, USA). All shots were performed from an artificial grass mat positioned on top of the Stewart Platform of a CAREN system (Motek Medical, Amsterdam, Netherlands), which was used to create uphill and downhill slopes of $5^{\circ}$ (Figure 2). Golfers wore their own golf shoes and glove. The order of shots was randomised across all conditions. Kinematic data were collected using 12 Bonita B10 cameras (Vicon, Oxford Metrics Group, UK) sampling at $250 \mathrm{~Hz}$. A golfer marker set consisting of 45 markers was used to track full body motion, the club was modelled using retro-reflective tape placed at three points along the shaft and two markers placed on the heel and toe end of the club and one on the top of the shaft. The ball was modelled using retro-reflective tape on its surface and was additionally tracked using a Foresight GC2 launch monitor (Foresight Sports, US). The simulated ball flight derived from the launch monitor data was projected onto a screen in front of the golfer to provide feedback of the shot outcome (Figure 2). Force data were collected using two $0.4 \times 0.6 \mathrm{~m}$ strain gauge force plates (FP4060-07, Bertec Corporation, Ohio, USA) sampling at $1000 \mathrm{~Hz}$ which were topped with two non-overlapping artificial grass mats. A further four markers were placed on the Stewart platform surface to track the position and orientation of the platform in order to correct errors introduced into the force plate measures. ${ }^{18}$ The origin of the capture volume $(3 \times 3 \times 3 \mathrm{~m})$ was positioned at the front centre of the two force plates and the global coordinate system was set with positive $x$ in the direction of the shot and positive $z$ pointing upwards (Figure 2).

\section{Data Analysis}

Force platform data is usually expressed relative to a static global coordinate system. Movement of the platform away from the neutral orientation and position at system calibration results in an offset to force plate outputs. ${ }^{18}$ BodyLanguage code was used to reconstruct the corners of the force plates based on the four markers surrounding the platform. These points were used to recreate the force plate local coordinate systems so that COP and feet markers could be transformed into the same coordinate system for COP to be calculated relative to feet marker positions. Data from the two force plates was combined and COP was smoothed using a $15 \mathrm{~Hz}$ Butterworth low pass digital filter. ${ }^{8,19,20}$ The COP in the direction of the shot was normalised to a percentage of the distance between the right and left foot centres (average of heel and toe marker for each foot), with 0\% representing the back foot (right) and 100\% the front foot (left). 
Eight events commonly used as coaching indicators were identified during the golf swing action (Figure 1, Table 1) so that COP at these key positions could be evaluated for each slope condition. ${ }^{5}$

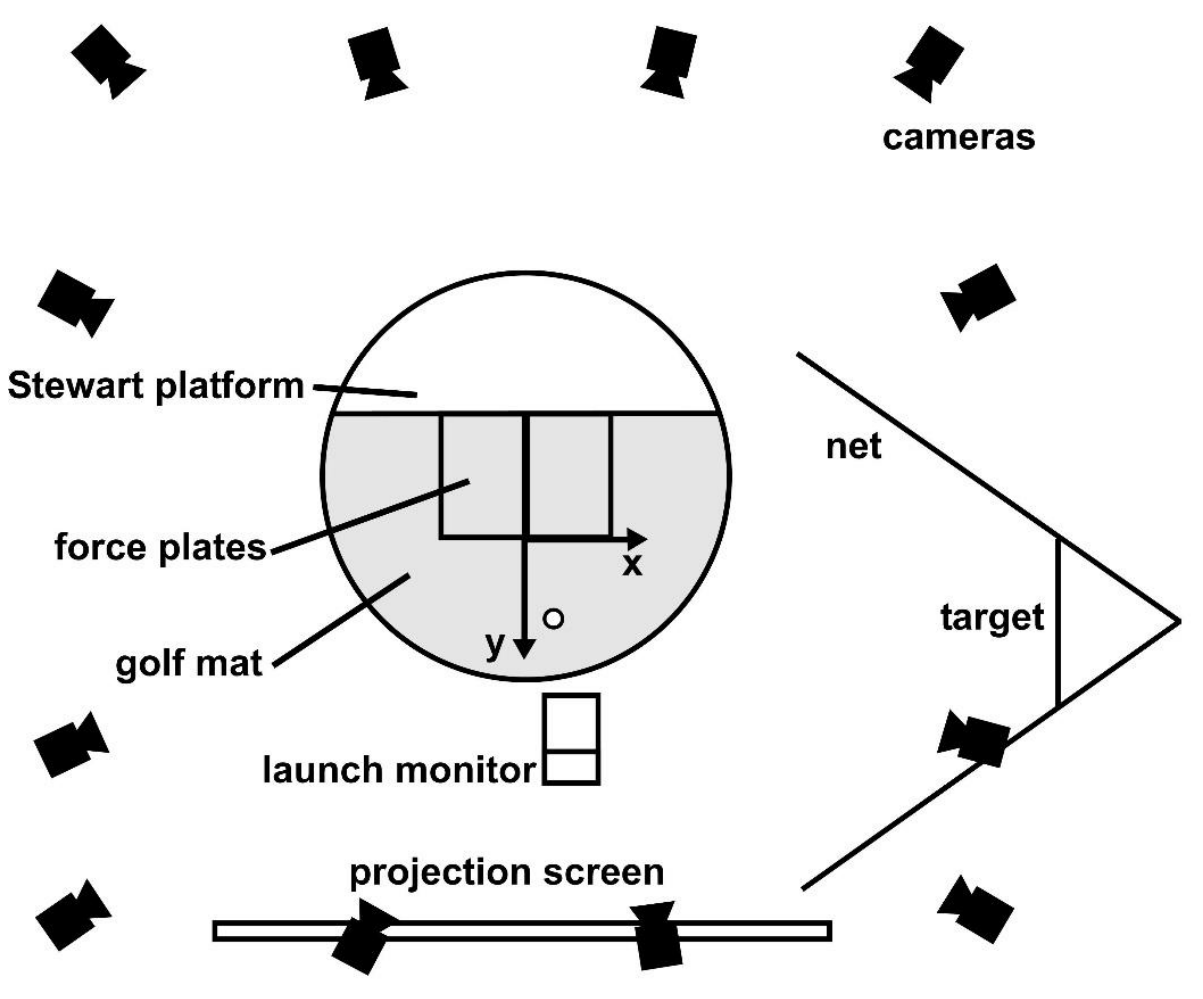

(a)
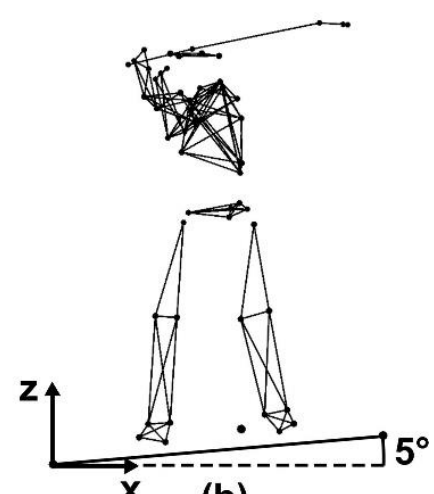

(b)

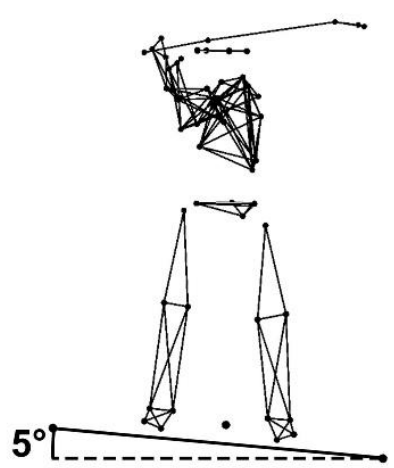

(c)

Figure 2. Schematic of (a) data collection set up with depiction of the (b) uphill and (c) downhill slopes created by the CAREN platform.

Table 1. Definition of golf swing events as used by Ball and Best (2007)

\begin{tabular}{lll}
\hline Event & Description & Label \\
\hline Takeaway & First backward movement of the club & TA \\
Mid backswing & Club shaft parallel to horizontal plane & MB \\
Late backswing & Club shaft perpendicular to horizontal plane & LB \\
Top backswing & Instant before shaft begins downswing & TB \\
Early downswing & Club shaft perpendicular to horizontal plane & ED \\
Mid downswing & Club shaft parallel to horizontal plane & MD \\
Ball contact & Instant of club contact with ball & BC \\
Mid follow-through & Club shaft parallel to horizontal plane & MF \\
\hline
\end{tabular}


The position of the ball at take away (TA) was expressed as a percentage of the distance between the right and left foot centres and the distance on the y-axis from the point of mid stance (Figure 3). The absolute distance between the foot centres was also recorded for each shot. The alignment of the golfer at take away and ball contact was assessed from the projection of the lines between foot, hip and shoulder centres onto the horizontal plane of the global coordinate system and was measured relative to the direction of the shot (global $x$ direction, Figure 3). ${ }^{21}$ An angle of zero corresponds to parallel to the line from tee to target with negative angles indicating a setup pointing to the left of target and positive angle pointing to the right. ${ }^{22}$ The inclination angle of the hips and shoulders relative to the slope was determined at take away from the projection of the lines between hip and shoulder joint centres onto the frontal plane of the global coordinate system.

Performance outcomes were measured using the Foresight GC2 launch monitor and included: the rate the ball left the club face (ball speed), the angle relative to the horizontal plane that the ball left the club face (launch angle), direction the ball left the club face relative to the target line (azimuth), the direction and magnitude the ball spins (side spin), the perpendicular distance the ball would have landed away from the target line (offline) and total shot distance.
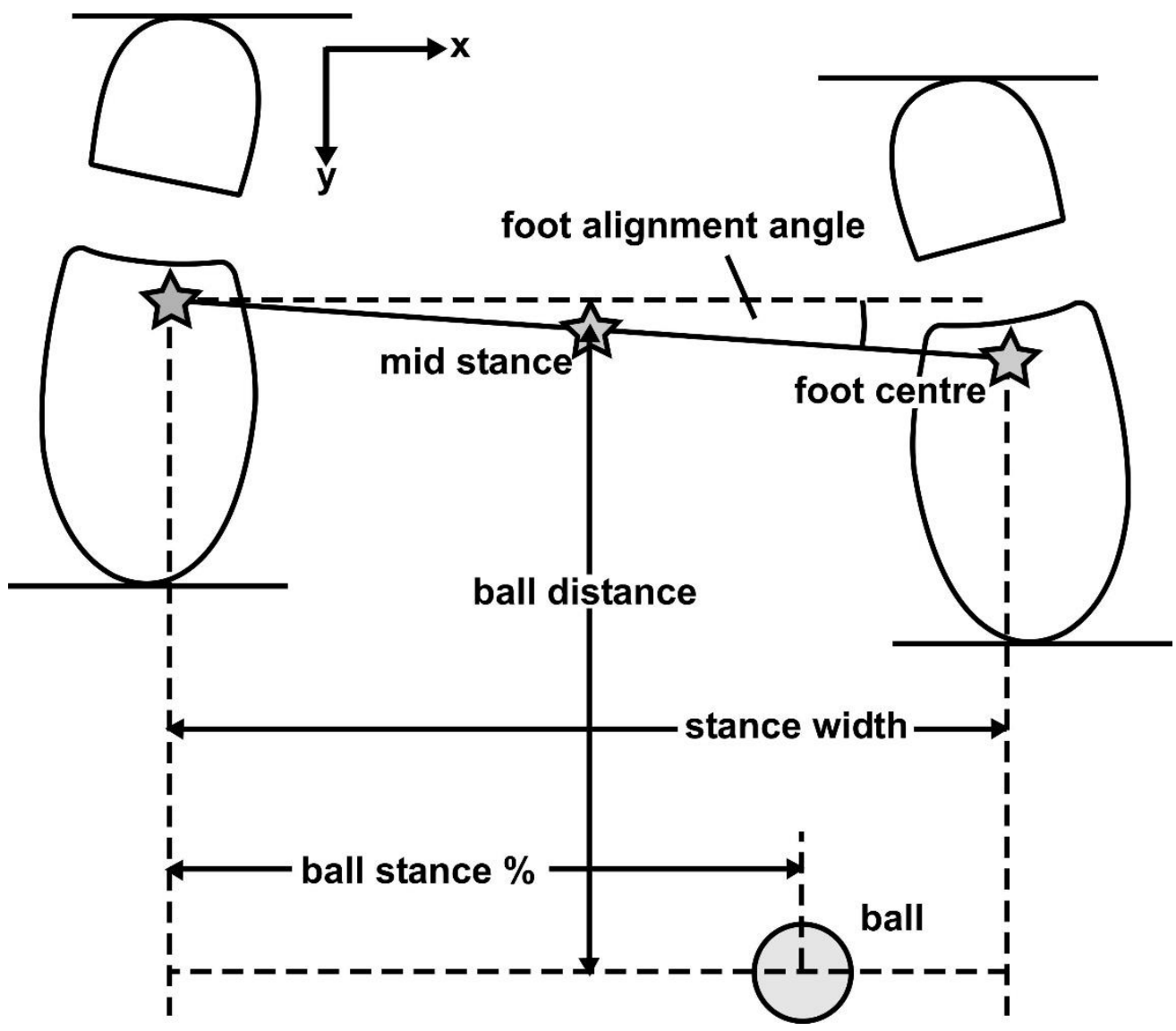

foot alignment angle

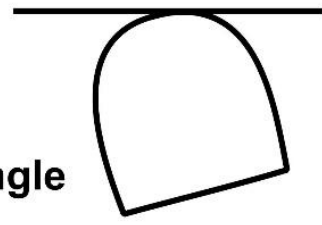

Figure 3. Definition of ball and stance measures.

\section{Statistical Analysis}

Trials were combined to create a mean score for each subject under each condition (flat, uphill, downhill) before further analysis. Repeated measures one-way ANOVA's were used to assess the differences in COP position, alignment and performance outcomes between flat, uphill and downhill slopes. Post hoc tests were made using multiple repeated measures t-Tests with a Bonferroni correction. All data were assessed 
for normality and sphericity by the Shapiro-Wilk test and Mauchly's test of sphericity. All data were found to be normally distributed, and for those data that violated the assumption of sphericity a Greenhouse-Geisser correction was used. ${ }^{23}$ The significance level was set to 0.05 and partial eta squared (n2) was used to calculate the effect size $($ small $=0.01$, medium $=0.06$ and large $=0.14) .{ }^{24}$

\section{RESULTS}

A general shift in the position of the COP was found throughout the golf swing for all participants on uphill and downhill slopes (Figure 4). Repeated measures one-way ANOVA showed there was a significant difference $(p<0.001)$ between the position of the COP at each swing event with a large effect size (Table 2). The mean position of the COP moved approximately $9.4 \%$ closer to the front foot for the downhill slope and $8.9 \%$ closer to the back foot for the uphill slope. The general pattern of the centre of pressure remained unchanged between the three different conditions (Figure 4).

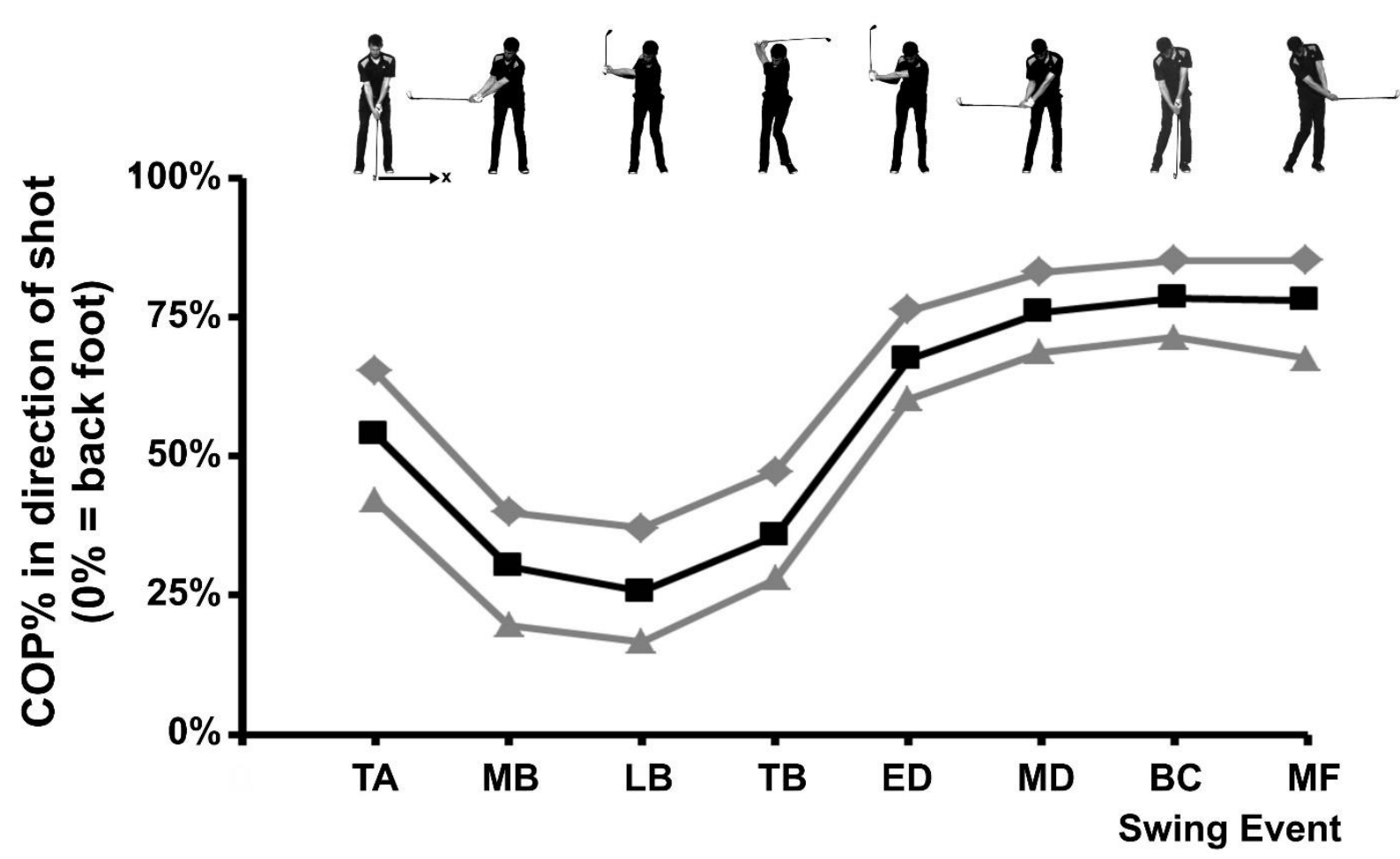

Figure 4. Group mean position of COP between the back foot $(0 \%)$ and front foot $(100 \%)$ for flat (black squares), uphill (grey triangles) and downhill (grey diamonds) lies at each swing event (Table 1).

At address (take away) stance width was found to be significantly wider for the uphill and downhill slopes compared to the flat condition (Table 3). There were no significant differences in ball position between the flat and two sloped conditions (Table 3). However, the ball was placed significantly further forward (towards the front foot) in the stance for the uphill compared to the downhill slope (Table 3). In the uphill condition, the ball was positioned further away (Table 3, ball distance) from the golfer (Table 3), however, for downhill there was no statistical difference from the flat condition (Table 3). 
Table 2. The position of centre of pressure (mean \pm standard deviation) between the back foot $(0 \%)$ and front foot $(100 \%)$ for flat, uphill and downhill conditions at each swing event (Table 1)

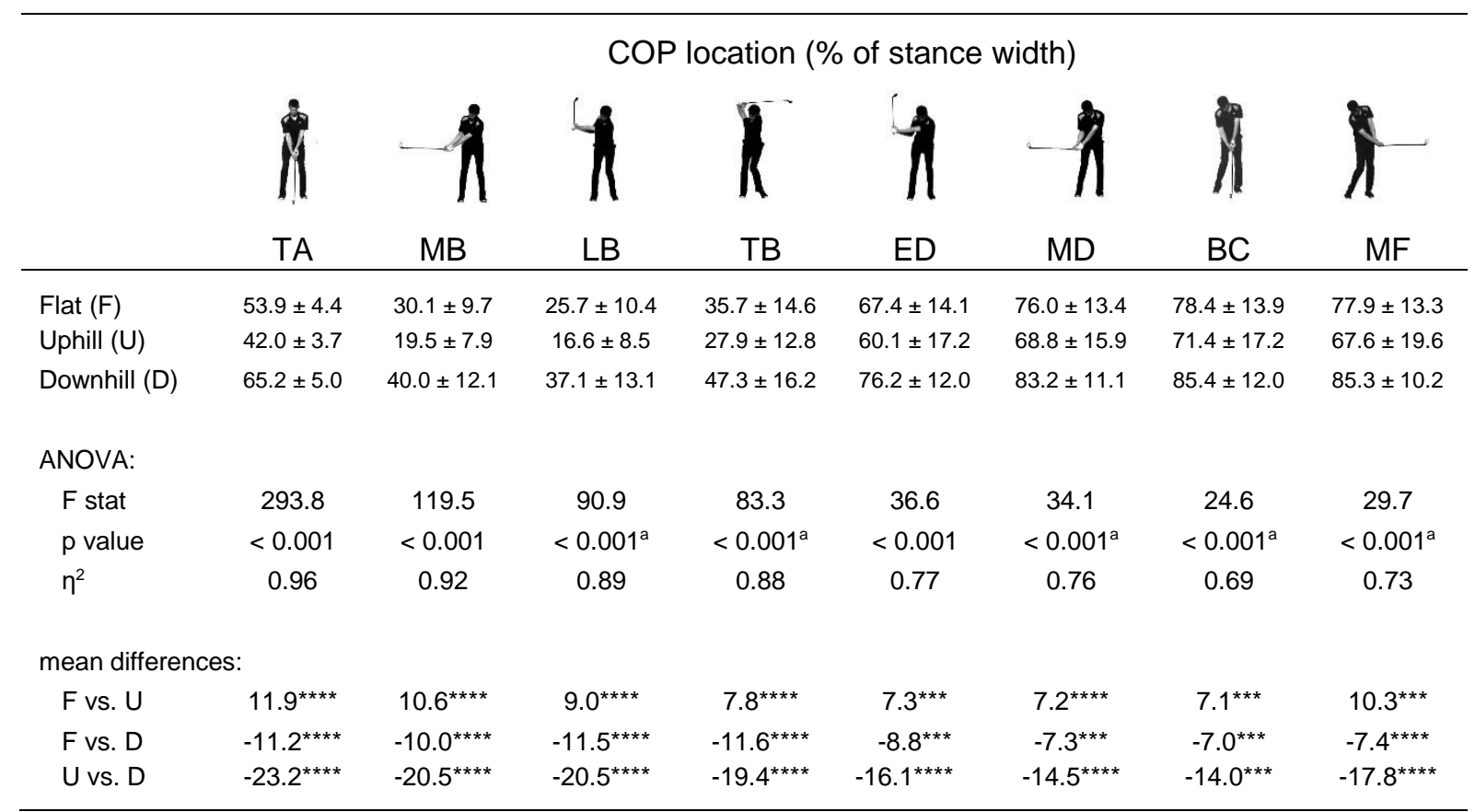

Note: Significant comparisons are indicated by ${ }^{* * *}(p<0.005),{ }^{* \star * *}(p<0.001)$; tests requiring a Greenhouse-Geisser correction are indicated by ${ }^{a}$.

Table 3. Foot and ball positions (mean \pm standard deviation) at take away (TA) and shoulder, hip and foot angles at take away and ball contact (BC) for flat, uphill, and downhill

\begin{tabular}{|c|c|c|c|c|c|c|c|c|c|c|}
\hline \multirow[b]{3}{*}{ Swing event } & \multirow{3}{*}{$\begin{array}{l}\text { Stance width } \\
\quad(\mathrm{mm})\end{array}$} & \multirow{3}{*}{$\begin{array}{l}\text { Ball position } \\
(\%)\end{array}$} & \multirow{3}{*}{$\begin{array}{l}\text { Ball distance } \\
\qquad(\mathrm{mm})\end{array}$} & \multirow{3}{*}{$\begin{array}{c}\text { Foot angle }\left(^{\circ}\right) \\
\text { Alignment } \\
\text { TA }\end{array}$} & \multicolumn{3}{|c|}{ Hip angles $\left(^{\circ}\right)$} & \multicolumn{3}{|c|}{ Shoulder angles $\left({ }^{\circ}\right)$} \\
\hline & & & & & \multicolumn{2}{|c|}{ Alignment } & \multirow{2}{*}{$\begin{array}{l}\text { Tilt } \\
\text { TA }\end{array}$} & \multicolumn{2}{|c|}{ Alignment } & \multirow{2}{*}{$\begin{array}{l}\text { Tilt } \\
\text { TA }\end{array}$} \\
\hline & & & & & TA & $\mathrm{BC}$ & & TA & $\mathrm{BC}$ & \\
\hline Flat (F) & $471.3 \pm 42.1$ & $61.9 \pm 6.9$ & $736.4 \pm 44.0$ & $-0.3 \pm 3.7$ & $-2.5 \pm 5.5$ & $-39.0 \pm 8.6$ & $10.7 \pm 8.4$ & $-4.7 \pm 3.1$ & $-2.5 \pm 6.3$ & $12.2 \pm 3.2$ \\
\hline Uphill (U) & $483.5 \pm 33.6$ & $64.5 \pm 8.3$ & $745.1 \pm 47.5$ & $-0.6 \pm 3.5$ & $-4.6 \pm 6.4$ & $-39.3 \pm 9.1$ & $10.6 \pm 8.4$ & $-5.3 \pm 3.7$ & $-2.1 \pm 7.0$ & $11.2 \pm 3.3$ \\
\hline Downhill (D) & $484.2 \pm 34.2$ & $58.2 \pm 9.4$ & $731.1 \pm 44.0$ & $-0.7 \pm 3.6$ & $-2.1 \pm 6.4$ & $-39.7 \pm 9.3$ & $11.1 \pm 8.4$ & $-4.7 \pm 4.3$ & $-4.4 \pm 6.7$ & $14.2 \pm 3.3$ \\
\hline \multicolumn{11}{|l|}{ ANOVA: } \\
\hline F statistic & 5.9 & 10.2 & 6.5 & 0.8 & 10.4 & 0.4 & 1.4 & 0.9 & 7.9 & 26.0 \\
\hline$p$ value & $<0.01$ & $<0.005$ & $<0.01$ & $>0.05^{\mathrm{a}}$ & $<0.005$ & $>0.05$ & $>0.05^{\mathrm{a}}$ & $>0.05$ & $<0.005$ & $<0.001$ \\
\hline$\eta^{2}$ & 0.35 & 0.48 & 0.37 & 0.07 & 0.49 & 0.03 & 0.11 & 0.07 & 0.42 & 0.70 \\
\hline \multicolumn{11}{|l|}{$\begin{array}{l}\text { mean } \\
\text { differences: }\end{array}$} \\
\hline Fvs. U & $-12.2^{*}$ & -2.6 & $-8.8^{*}$ & 0.3 & $2.1^{* \star *}$ & 0.2 & 0.1 & 0.6 & -0.5 & $1.0^{*}$ \\
\hline Fvs. D & $-12.9^{\star}$ & 3.7 & 5.3 & 0.4 & -0.4 & 0.6 & -0.4 & -0.0 & $1.9^{* *}$ & $-2.0^{\star \star \star *}$ \\
\hline U vs. D & -0.7 & $6.3^{\star *}$ & $14.1^{*}$ & 0.1 & $-2.5^{\star \star}$ & 0.4 & -0.5 & -0.6 & $2.4^{*}$ & $-3.0^{* \star \star \star}$ \\
\hline
\end{tabular}

Note: Significant comparisons are indicated by ${ }^{*}(\mathrm{p}<0.05),{ }^{* *}(\mathrm{p}<0.01),{ }^{* *}(\mathrm{p}<0.005),{ }^{* * * *}(\mathrm{p}<0.001)$; tests requiring a Greenhouse-Geisser correction are indicated by a.

There were no significant differences in foot and shoulder alignment during the three different conditions at address (Table 3). However, the hip alignment angle for uphill was significantly smaller (pointing to the left of target) compared to the flat and downhill conditions (Table 3). The hip inclination angle relative to the surface was not significantly different between the three slope conditions. The shoulder inclination angle 
was significantly different between all three slope conditions. At ball contact, there were no differences in foot and hip alignment across the three conditions. However, the shoulder alignment for the downhill slope was significantly smaller (to the left of target) compared to the uphill and flat conditions.

Performance outcomes measured by the Foresight GC2 launch monitor showed no significant difference in ball speeds or azimuth between the three slopes (Table 4). However, there were significant differences for launch angle, spin rate, and offline displacement between all conditions, with shots on the uphill slope displaying more spin to the left and a greater offline distance to the left of the target (Table 4). Compared to the flat, there was a significant increase in launch angle for uphill, with a subsequent significant decrease for downhill. Significant changes in offline displacement and side spin were also found (Table 4).

Table 4. Performance outcomes measured (mean \pm standard deviation) by the launch monitor for flat, uphill, and downhill

\begin{tabular}{|c|c|c|c|c|c|c|}
\hline & $\begin{array}{l}\text { Ball speed } \\
\text { (mph) }\end{array}$ & $\begin{array}{c}\text { Launch angle } \\
\left({ }^{\circ}\right)\end{array}$ & $\begin{array}{l}\text { Azimuth } \\
\left({ }^{\circ}\right)\end{array}$ & $\begin{array}{l}\text { Side spin } \\
\text { (rpm) }\end{array}$ & $\begin{array}{l}\text { Distance } \\
\text { (yards) }\end{array}$ & $\begin{array}{l}\text { Offline } \\
\text { (yards) }\end{array}$ \\
\hline Flat $(F)$ & $123.4 \pm 4.0$ & $15.4 \pm 1.5$ & $0.0 \pm 2.1$ & $-125.1 \pm 464.2$ & $186.9 \pm 5.1$ & $-2.9 \pm 12.6$ \\
\hline Uphill (U) & $122.8 \pm 3.6$ & $19.1 \pm 1.8$ & $-0.3 \pm 1.8$ & $-386.6 \pm 284.8$ & $183.6 \pm 4.1$ & $-8.4 \pm 9.4$ \\
\hline Downhill (D) & $122.2 \pm 4.4$ & $11.8 \pm 1.4$ & $-0.6 \pm 2.1$ & $122.6 \pm 395.7$ & $185.2 \pm 6.2$ & $-0.5 \pm 9.7$ \\
\hline \multicolumn{7}{|l|}{ ANOVA: } \\
\hline F stat & 3.4 & 124.8 & 1.7 & 17.7 & 4.2 & 10.3 \\
\hline$p$ value & $>0.05$ & $<0.001^{\mathrm{a}}$ & $>0.05$ & $<0.001$ & $<0.05$ & $<0.005$ \\
\hline$\eta^{2}$ & 0.24 & 0.92 & 0.14 & 0.62 & 0.28 & 0.48 \\
\hline \multicolumn{7}{|c|}{ mean differences: } \\
\hline F vs. U & 0.6 & $-3.7^{\star \star \star \star}$ & 0.3 & $261.5^{\star}$ & $3.3^{*}$ & $5.4^{*}$ \\
\hline F vs. D & 1.2 & $3.6^{\star * \star \star}$ & 0.7 & -247.6 & 1.7 & -2.4 \\
\hline U vs. D & 0.6 & $7.3^{\star \star \star \star}$ & 0.3 & $-509.1^{* * * *}$ & -1.6 & $-7.8^{\star \star \star}$ \\
\hline
\end{tabular}

Note: Significant comparisons are indicated by ${ }^{*}(p<0.05),{ }^{* * *}(p<0.005),{ }^{* * *}(p<0.001)$; tests requiring a Greenhouse-Geisser correction are indicated by a.

\section{DISCUSSION}

The aim of the present study was to examine changes in weight transfer, direction of aim (alignment) and performance outcomes during golf shots from flat, uphill, and downhill slopes. A CAREN system was used to create the different slopes and collect kinetic and kinematic data. The general pattern of the COP relative to the stance width at various swing points (Figure 4) followed the pattern reported by Ball and Best. ${ }^{5}$ The COP moves toward the back foot during the backswing then shifts rapidly forward at the start of the downswing and stayed closer to the front foot through ball contact (Figure 4). These patterns remained largely unchanged with the introduction of uphill and downhill slopes, however, there was a systematic shift in COP of approximately $9 \%$ towards the lower foot (Figure 4). Ball and Best analysed weight transfer for golfers using a driver. ${ }^{1,5,20}$ The pattern displayed by all golfers was very similar to those obtained in the present study (Figure 4) with golfers who used a six-iron. The majority of players (approx. 63\%) analysed by Ball and Best demonstrated a shift in COP from back foot to front foot from the top of the backswing through ball contact (Figure 1). ${ }^{5} \mathrm{~A}$ second, smaller group (approx. 31\%) followed the same pattern during the downswing but shifted the weight towards the back foot (reverse group) at ball contact (Figure 1, grey data). ${ }^{5}$ These patterns were present for players across a range of different clubs 
(driver, 3-iron and 7-iron), with $96 \%$ of players maintaining their grouping with each club.25 Only two of the 12 golfers in the present study demonstrated a "reverse" shift in the flat condition, which they maintained on the slopes. However, two further golfers switched to a "reverse" pattern on the uphill slope. Since the weight systematically moves towards the back foot on an uphill slope (i.e. the lower foot), golfers should be careful not to allow too much weight to move to the lower foot, as recommended by the coaching literature, since this may result in contacting the ground behind the ball. ${ }^{12,15}$ It would be interesting to determine whether this switch in pattern is more prevalent in higher handicap golfers, who may be less able to adapt to the slope, or whether the change occurs more frequently on larger slopes.

The coaching advice for playing on uphill and downhill slopes suggests the golfer sets the body perpendicular to the playing surface and adopts a wider, more stable, stance. ${ }^{12,14,15}$ In the present study, golfers followed the coaching advice and adopted a wider stance on both slopes (Table 3). There were no statistical differences in the hip inclination angle relative to the playing surface for the three conditions (Table 3) suggesting that at the level of the hips the players were adopting the advice. At the shoulder level, while the golfers, on average, adjusted in the direction of being perpendicular to the surface, in both the uphill and downhill directions a complete $5^{\circ}$ shift was not achieved (Table 3). Harmon, states that based on experience achieving shoulders parallel to the surface is particularly difficult on a downhill slope, this is most likely due to people preferring to stand with the body parallel to the gravity line. ${ }^{15}$ With the hip inclination angle maintained on the slope more weight is transferred to the lower foot, causing the general weight shift to the back foot on uphill and to the front foot on downhill slopes (Figure 4).

In addition to adopting a wider stance Leadbetter advises moving the ball nearer the front foot for uphill slopes (i.e. increasing the ball position \%) and nearer the back foot for downhill slopes. ${ }^{12}$ Although there were no statistically significant differences between the flat and the two sloped conditions (Table 3), the ball was placed (ball position \%) significantly closer to the front foot for the uphill condition compared to the downhill condition (Table 3). In other words, there was not a consistent response to the slope that followed the coaching advice compared to the flat. However, all golfers played the ball relatively further forward in the stance for uphill verses downhill slopes. If the golfer has not achieved a full shoulder tilt (to parallel with the surface) on a downhill slope Harmon suggests that this can lead to striking behind the ball. ${ }^{15}$ Therefore, moving the ball toward the back foot on a downward slope would be of benefit. A similar explanation for moving the ball forward on an uphill slope can also be made.

There will be systematic differences between the estimation of the shot outcome values used compared to recording the whole flight path of the ball. ${ }^{26}$ The performance data was collected using a commercially available launch monitor (Foresight GC2), which uses a portion of the flight path to predict the final shot outcomes. However, it has been shown that the Foresight GC2 compares very well with "gold standard" measures of ball flight measurements such as ball speed, launch angle and spin rate. ${ }^{26}$ Foresight launch monitor data has been compared with a GOM Inspect (GOM mbH, Germany), which is reportedly accurate to $25 \mu \mathrm{m} . \mathrm{m}-1$ and found median difference values within acceptable tolerances levels (on average $<0.2 \mathrm{mph},<0.2^{\circ},<21 \mathrm{rpm}$, respectively). ${ }^{26}$

There were no significant differences in ball speeds or azimuth between the three slopes, despite the normalised effect sizes being classed as large (Table 4). ${ }^{24}$ However, there were significant differences for launch angle, spin rate, and offline displacement (Table 4). Compared to the flat, there is a significant increase in launch angle for uphill, with a subsequent significant decrease for downhill slopes, as might be expected if the 
golfer attempts to stay perpendicular to the surface. ${ }^{12}$ Harmon suggests taking a longer club for uphill shots as the increased launch angle often leads to a reduction in shot distance (Table 4). ${ }^{15}$ Significant changes in offline displacement and side spin suggest that, compared to the flat, uphill shots result in increased spin and movement of the ball towards the left for right handed golfers. Conversely, downhill shots result in more spin of the ball to the right and continued, but reduced, movement of the ball to the left. With very little change in azimuth between conditions, these results suggest the increased movement of the ball to the left for uphill shots was most likely due to the increased spin of the ball to the left, and the reduction of movement to the left from a downhill slope is most likely due to increased spin of the ball to the right. Increased spin and movement of the ball to the left would suggest golfers are at an increased risk of "hooking" the ball (an exaggerated draw) when playing shots from an uphill slope and "slicing" (an exaggerated fade) from a downhill slope. How mid and high handicap golfers (lower standard) respond to slopes may provide additional insight, as their ability to cope may less proficient.

To counter the effects of the spin placed on the ball from a sloping lie it has been suggested that golfers compensated for by rotating the trunk to the right or left of the target respectively. ${ }^{15}$ No differences (Table 3) were found in the alignment of the feet and the shoulders relative to the straight target for the sloped conditions at address (TA). However, for the uphill condition there was a significant change in alignment of the hips at address (Table 3), with the hips turned to the left of the target. This is in the opposite direction to the compensation recommended by Harmon. ${ }^{15}$ Rotating the hips to the left of target produces a slightly more "open" stance which is more likely to result in spin on the ball to the right, if the club is swung down the line of the target. ${ }^{12}$ However, at ball contact there were no significant differences in hip alignment across the three slope conditions (Table 3). All golfers rotated the hips to an open angle (pointing left of target) at ball contact (range $-21^{\circ}$ to $-56^{\circ}$, Table 3 ), whereas there was a mix of open and closed angles at the shoulders (range $-14^{\circ}$ to $12^{\circ}$ ), as found previously for shots from a flat surface. ${ }^{21}$ At ball contact, there was a significant difference in shoulder alignment for uphill verses downhill slopes, with the golfers tending to be more "open" (left of target) on the downhill slope. While this agrees with coaching literature on the direction of spin imparted on a ball played from a slope, more analysis of the swing technique, particularly the path of the club head, is required to determine the mechanism for generating the differences in ball spin for the different slope conditions. ${ }^{27,28,29}$ Indeed, Leach found that "for most golfers achieving a different shot trajectory is more than simply changing address position and swinging normally". ${ }^{17}$

When playing from uphill and downhill slopes expert golfers shift their weight in the direction of the lower foot. This was explained by golfers following coaching advice to remain perpendicular to the playing surface. All golfers achieved this at the hips, but a complete adjustment at the shoulders was not found. In addition to moving the weight towards the lower foot all golfers adopted a wider stance on both slopes, and the ball was played further forward in the stance for uphill compared to downhill slopes. There were few adjustments made to alignment at address and ball contact to counter the additional side spin created by playing from a slope. More detailed analysis of the clubhead path is required to determine what adjustments may have been taken. Generally, the golfers appeared to follow the coaching advice and the expected shot outcomes were found, however, there were individual responses to the slopes that did not follow the advice.

\section{Conflict of Interest}

The authors wish to disclose that they have no financial or personal relationships with any people or organisations that could inappropriately influence this work. 


\section{Acknowledgement}

The authors would like to thank the golfers who participated in the study for their time and Harry Coe for his assistance with the data collection.

\section{References}

1. Ball KA, Best RJ. Centre of pressure patterns in the golf swing: individual-based analysis. Sport Biomech. 2012;11(2):175-189.

2. Bradshaw EJ, Keogh JWL, Hume PA, et al. The effect of biological movement variability on the performance of the golf swing in high- and low-handicapped players. Res Quart Exercise Sport. 2009:80:185-196.

3. Healy A, Moran KA, Dickson J, et al. Analysis of the 5 iron golf swing when hitting for maximum distance. J Sport Sci. 2011:29(10):1079-1088.

4. Zheng N, Barrentine SW, Fleisig GS, et al. Kinematic analysis of swing in pro and amateur golfers. Int J Sport Med. 2008:29:487-493.

5. Ball KA, Best RJ. Different centre of pressure patterns within the golf stroke I: Cluster analysis. J Sport Sci. 2007:25(7):757-770.

6. McNitt-Gray JL, Munaretto J, Zaferiou A, et al. Regulation of reaction forces during the golf swing. J Sport Sci. 2013:12(2):121-131.

7. Okuda I, Gribble P, Armstrong C. Trunk rotation and weight transfer patterns between skilled and low skilled golfers. J Sports Sci Med. 2010:9:127-133.

8. Ball KA, Best RJ, Wrigley $T$, et al. Centre of pressure correlations with clubhead speed in the golf swing. In Blackwell JR, Sanders RH, eds. XIX International Symposium on Biomechanics in Sport. 2001:48-53.

9. Wallace ES, Graham D, Bleakley EW. Foot-to-ground pressure patterns during the golf drive: a case study involving a low handicap player and a high handicap player. In Science and golf: Proceedings of the First World Scientific Congress of Golf. London: E \& FN Spon. 1990:25-29.

10. Peterson TJ, Wilcox RR, McNitt-Gray JL. Angular impulse and balance regulation during the golf swing. J Appl Biomech. 2016:32:342-349.

11. Peters R, Smith M, Lauder M. (2015). Quantifying the gradients exposed to a professional golfer during a round of golf. In Colloud F, Domalain M, Monnet T, eds. 33rd International Conference on Biomechanics in Sports. 2015:1153-1156.

12. Leadbetter D. Faults and fixes: The golfer's essential problem-solving manual. London: Collins Willow; 1993.

13. Norman G. Advanced golf. Port Melbourne VIC: Heinemann.Sciences, 1995:2:165176.

14. Hunter, R. (2010). Junior Golf Coaching with Rupert Hunter. Series 2: Lesson Seven - Awkward Lies. Golf Today, Hunter Knight Golf Coaching.

15. Harmon B. Four shots for beating the slope. 2011. Available at https://www.golfdigest.com/story/butch-harmon-uneven-lies [Accessed August 2017].

16. Coleman S, Anderson D. An examination of the planar nature of golf club motion in the swings of experienced players. J Sport Sci. 2007:25(7):739-748.

17. Leach RJ. The role of biomechanics in achieving different shot trajectories in golf. Doctoral Thesis submitted in partial fulfilment of the requirement for the award of Doctor of Philosophy of Loughborough University. 2017.

18. Preuss R, Fung J. (2004). A simple method to estimate force plate inertial components in a moving surface. J Biomech. 2004:37(8):1177-1180.

19. Winter DA. Human balance and posture control during standing and walking. Gait Posture. 1995:3(4):193-214. 
20. Ball KA, Best RJ. Different centre of pressure patterns within the golf stroke II: Group-based analysis. J Sport Sci. 2007:25(7):771-779.

21. Burden AM, Grimshaw PN, Wallace ES. Hip and shoulder rotations during the golf swing of sub-10 handicap players. J Sport Sci. 1998:16:165-176.

22. Wheat JS, Vernon T, Milner CE. The measurement of upper body alignment during the golf drive. J Sport Sci. 2007:25:749-755.

23. Field A. P. Discovering statistics using SPSS. London, England: SAGE; 2009.

24. Cohen J. Statistical Power Analysis for the Behavioral Sciences. New York, NY: Routledge Academic; 1988.

25. Ball KA, Best RJ. Golf styles and centre of pressure patterns when using different golf clubs. J Sport Sci. 2011:29(6):587-590.

26. Leach RJ, Forrester SE, Smith AC, et al. How valid and accurate are measurements of golf impact parameters obtained using commercially available radar and stereoscopic optical launch monitors? Measurement. 2017:112:125-136. doi:http://dx.doi.org/10.1016/j.measurement.2017.08.009

27. Morrison A, McGrath D, Wallace ES. (2017). The relationship between the golf swing plane and ball impact characteristics using trajectory ellipse fitting. Journal of Sports Sciences. In Press. Available at http://dx.doi.org/10.1080/02640414.2017.1303187 [Accessed, July 2017]

28. Leadbetter D. The easy way to hit fades and draws. 2010. Available at http://www.golfdigest.com/story/leadbetter-draw-fade [Accessed August 2017].

29. Collinson, A. R., Wood, P., Mullineaux, D. R, et al. The clubhead swing plane in golf draw and fade shots. In Proceedings of the BASES Biomechanics Interest Group Meeting; 2012:17. 